\title{
Relaxant Effects of Quercetin and Rutin on Human Isolated Bronchus
}

\author{
Hanifa Djelili ${ }^{1}$, Lekhmici Arrar ${ }^{1}$, Emmanuel Naline $^{2}$, Philippe Devillier $^{2}$ \\ ${ }^{1}$ Laboratory of Applied Biochemistry, Department of Biochemistry, Faculty of Nature and Life Sciences, \\ University Ferhat Abbas, Setif, Algeria \\ ${ }^{2}$ Faculty of Medicine Paris Ile-de-France West, UPRES EA220, Foch Hospital, \\ Suresnes, France \\ Email: lekharrar@hotmail.com
}

Received April 20, 2012; revised May 10, 2012; accepted May 18, 2012

\begin{abstract}
Increasing epidemiological evidence supports the view, that quercetin has protective roles in a multitude of disease states in human who have a high intake of polyphenols. To investigate the ability of quercetin and its rutinoside, rutin, to modulate the relaxation of human airways smooth muscle and to determine the mechanism (s) of such relaxation, isolated human bronchus rings were suspended in individual organ baths, precontracted with acetylcholine or with histamine and the relaxing effects of quercetin and rutin were determined by measurement of isometric tension. Quercetin induced concentration-dependent relaxant responses on acetylcholine or histamine precontracted human bronchial rings and with almost equal effectiveness. In terms of potency $\left(\mathrm{pD}_{2}\right)$ and efficacy $\left(\mathrm{E}_{\max }\right)$, quercetin is more potent than rutin on relaxant responses of human bronchus. $\mathrm{K}^{+}$and $\mathrm{Ca}^{2+}$ concentration-dependent contraction curves were inhibited after incubation with increasing concentrations of quercetin. Quercetin potentiated in a concentration-dependent manner the relaxant effects of isoprenaline or sodium nitroprusside. Rutin had no effect on $\mathrm{K}^{+}$-induced contraction and on relaxant activity of isoprenaline or sodium nitroprusside. Our results suggest that the bronchodilator effects of quercetin are modulated by an increase in cyclic nucleotide levels as well as an alteration in availability of $\mathrm{Ca}^{2+}$ to the contractile machinery.
\end{abstract}

Keywords: Calcium Channels; Cyclic Nucleotide; Human Bronchus; Quercetin; Relaxant Effects; Rutin

\section{Introduction}

Several epidemiological studies have shown a beneficial link between dietary flavonols intake and reduced risk of chronic disease. The beneficial effects of flavonoids on human health have been attributed to their antioxidant and anti-inflammatory properties [1]. Among flavonols, quercetin is the most abundant in the human diet, accounting for about $60 \%$ of the total intake [2]. Quercetin is present mostly in the form of glycosides in plant foods such as vegetables and fruits. Almost 180 different glycosides of quercetin have been described in nature, with rutin (quercetin-3-O-rutinoside) being one of the most common [3]. Based on its polyphenol structure (Figure 1), quercetin exerts many beneficial health effects, including improvement of cardiovascular health, reducing risk for cancer, protection against osteoporosis $[2,4]$.

Most of these properties are linked to its strong antioxidant action but quercetin also modulates the expression of specific enzymes $[5,6]$. However, few studies have investigated the relationship between quercetin consumption and obstructive lung disease. In one epidemic- ological report with over 13,000 participants, it is found that dietary intake of flavonols (a subclass of flavonoids including quercetin and kaempferol) was positively associated with pulmonary function and inversely associated with chronic cough and breathlessness in Dutch Chronic obstructive pulmonary disease (COPD) patients $[7,8]$. Furthermore, intake of polyphenol-containing fruit was inversely correlated with COPD mortality in three European countries [9]. In addition to their antioxidant properties, quercetin show several interesting effects, including antispasmolytic effects [10-12]. A number of flavonoids have been reported to affect smooth muscle contractility in response to various agonists [13-15]. The precise mechanisms by which flavonoids exert their actions remain unclear. In the vascular smooth muscle, they reduce smooth muscle contraction, evoked by several spasmogens, with a mechanism probably due to alteration in the availability of $\mathrm{Ca}^{2+}$ to the contractile machinery or to their action on crucial enzyme systems of intracellular cascades [16-18]. The aim of our present study is to investigate the ability of quercetin and its rutinoside, rutin, 


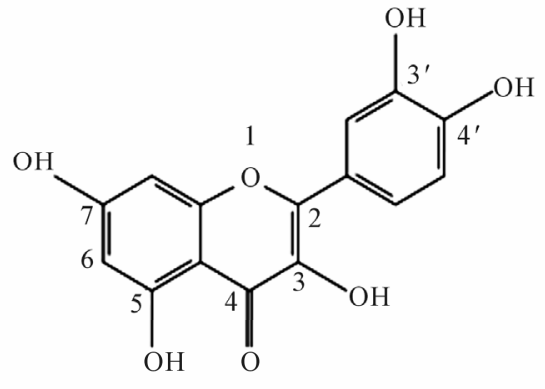

Quercetin

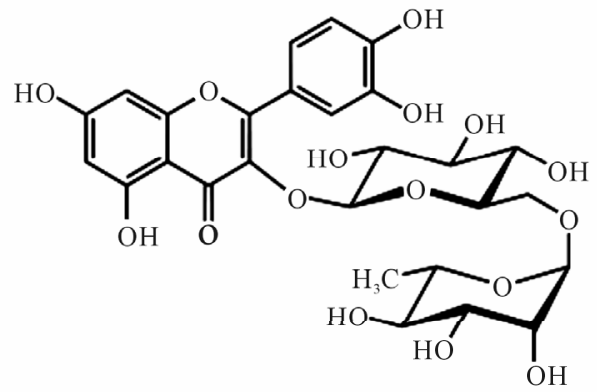

Rutin (Quercetin-3-O-rutinoside)

Figure 1. Chemical structure of quercetin and its rutinoside, rutin, tested.

to modulate the relaxation of human airways smooth muscle and to determine the mechanism (s) of such relaxation.

\section{Material and Methods}

\subsection{Isolated Human Airways}

Human bronchial tissues were obtained from thoracotomy specimens of patients undergoing surgery for lung carcinoma after consent of the patients. The protocol was approved by a local ethics committee. Specimens were selected from a macroscopically normal tissue at distance from the malignancy, and rapidly transferred to the laboratory in Krebs solution. After resection, segments of bronchi were carefully dissected from connective tissue and surrounding parenchyma and cut into rings. Human bronchial rings $(5-7 \mathrm{~mm}$ in length $\times 0.5$ $1 \mathrm{~mm}$ internal diameter) were either used immediately or stored overnight in a large volume of cooled $\left(4^{\circ} \mathrm{C}\right) \mathrm{Krebs}$ previously aerated. We found no functional differences in bronchial tissues that were studied immediately compared with those used after $24 \mathrm{~h}$ refrigeration.

\subsection{Airway Rings Bath Technique}

Bronchial human rings were placed in organ bath chamber containing $5 \mathrm{ml}$ of fresh Krebs solution that was replaced continuously, and bubbled with $95 \% \mathrm{O}_{2}-5 \% \mathrm{CO}_{2}$ at $37^{\circ} \mathrm{C}$. The airways were mounted between stainless steel hooks under a resting tension of 2 to $2.5 \mathrm{~g}$ and allowed to equilibrate for $1 \mathrm{~h}$. Changes in force of contraction were measured isometric with strain gauges (UF-1; Piodem, Canterbury, Kent, UK) and EMKA amplifiers (EMKA Technology, Les Ulis, France). In all experiments, the bronchial rings were first contracted maximally with acetylcholine ( $3 \mathrm{mM}$ ) and then relaxed, at the end of experiments without washout, with aminophylline $(3 \mathrm{mM})$ to obtain the maximal relaxation. Before beginning experiments, the human airways were allowed to equilibrate for $1 \mathrm{~h}$ during which the Krebs solution was changed every $15 \mathrm{~min}$.

\subsection{Effect of Quercetin or Rutin on Histamine- or Acetylcholine-Induced Contraction of Human Bronchi}

Following the second equilibration period, the cumulative concentration-response curves for quercetin or for rutin were obtained on bronchial rings contracted to $50 \%$ $60 \%$ of the maximal contraction with acetylcholine $10^{-6}$ $\mathrm{M}$ or histamine $10^{-5} \mathrm{M}$. When a steady level of contraction has been reached, quercetin and rutin were cumulatively added, with half $\log$ increments, to the bathing solution every $30 \mathrm{~min}$ when a steady-state effect has been reached. The maximal relaxant response elicited by aminophylline $(3 \mathrm{mM})$ was taken as $100 \%$. Only one concentration-response curve to a drug was recorded in each ring.

\subsection{Effect of Quercetin or Rutin on KCl- or $\mathrm{CaCl}_{2}$-Induced Contraction of Human Bronchus}

In order to test the potential action of quercetin and rutin as calcium antagonists, the inhibitory effect of these compounds was tested on the contraction induced by cumulative addition of $\mathrm{KCl}$ (3.75 to $75 \mathrm{mM})$ [19] and on the contraction directly caused by extracellular calcium $\left(\mathrm{CaCl}_{2}\right)$ added to the bath in a depolarising medium. $\mathrm{CaCl}_{2}$ concentration-response curves were established according to Advenier, et al. [20]. Briefly, human bronchial rings were incubated for $1 \mathrm{~h}$ in Krebs solution devoid of $\mathrm{CaCl}_{2}$ then for $15 \mathrm{~min}$ in $\mathrm{CaCl}_{2}$-free Krebs solution containing $1 \mathrm{mM}$ ethylenediaminetetraacetic acid. The preparations were washed with $\mathrm{CaCl}_{2}$-free Krebs solution and then incubated with Krebs solution containing $30 \mathrm{mM} \mathrm{KCl}$ (the concentration of $\mathrm{NaCl}$ was reduced to preserve isomolality). Concentration-response curves to $\mathrm{CaCl}_{2}(0.01$ to $3 \mathrm{mM})$ or to $\mathrm{KCl}(3.75$ to $75 \mathrm{mM})$ were then obtained in presence of quercetin, rutin or an equivalent volume of vehicle added to the bath $15 \mathrm{~min}$ before 
addition of $\mathrm{CaCl}_{2}$ or $\mathrm{KCl}$.

\subsection{Effect of Quercetin and Rutin on Concentration-Response Curves to Isoprenaline and Sodium Nitroprusside}

In another series of experiments, the airway rings were pretreated for $30 \mathrm{~min}$ with one concentration $\left(10^{-5}, 3 \times\right.$ $10^{-5}$ or $10^{-4} \mathrm{M}$ ) of quercetin of rutin or an equivalent volume of vehicle. Concentration-response curves to isoprenaline or sodium nitroprusside were then obtained by cumulative addition on bronchial rings contracted to a level similar to the controls. At the end of the relaxant response, aminophylline $(3 \mathrm{mM})$ was added to determine the maximum relaxation achievable.

\subsection{Drugs}

Isoprenaline, aminophylline ( $\mathrm{PCH}$, Paris, France); and acetylcholine (Glaxo, Paris, France), sodium nitroprusside (SNP), (Sigma, L'Isle d'Abeau, France). Quercétine and rutine (Fluka Chemikalien $\mathrm{GmbH}$ Buchs, Suisse). All stock solutions of the chemicals were made in distilled water excepted quercetin, and rutin in dimethyl sulfoxide (DMSO). All the stock solutions were kept frozen until use and then diluted in distilled water. No significant vehicle effect was observed.

\subsection{Statistical Analysis}

The relaxation responses were expressed as a percentage of the maximal relaxation produced by aminophylline (3 $\mathrm{mM}) . \mathrm{pD}_{2}$ value represents the negative logarithm of the concentration $\left(\mathrm{EC}_{50}\right)$ of drug which induces a relaxation equal to $50 \%$ of its own maximal effect. $\mathrm{EC}_{50}$ was determined from each relaxation curve by a logistic curvefitting equation. $E_{\max }$ represents the maximal effect of drug expressed as a percentage of the maximal relaxation to aminophylline. For the studies on the inhibitory activity of quercetin on $\mathrm{KCl}$ - and $\mathrm{CaCl}_{2}$-induced contractions, results are expressed as percentages of the maximal contraction induced by $\mathrm{KCl}(75 \mathrm{mM})$ and acetylcholine $\left(10^{-6}\right.$ $\mathrm{M})$, respectively. All values are expressed as mean \pm standard error of estimate mean value (s.e. mean). Differences between treatments were tested using analysis of variance (ANOVA) for repeated measures followed by Bonferroni-Dunn's test if required and the $\mathrm{pD}_{2}$ values were compared by Student's $t$-test (GraphPad). $\mathrm{p}<0.05$ was considered to be significant.

\section{Results and Discussion}

Relaxation of human isolated bronchus is clearly observed in the presence of quercetin in a concentrationdependent manner (Figure 2). In a first series of experiments, a comparing of the relaxant effect of quercetin

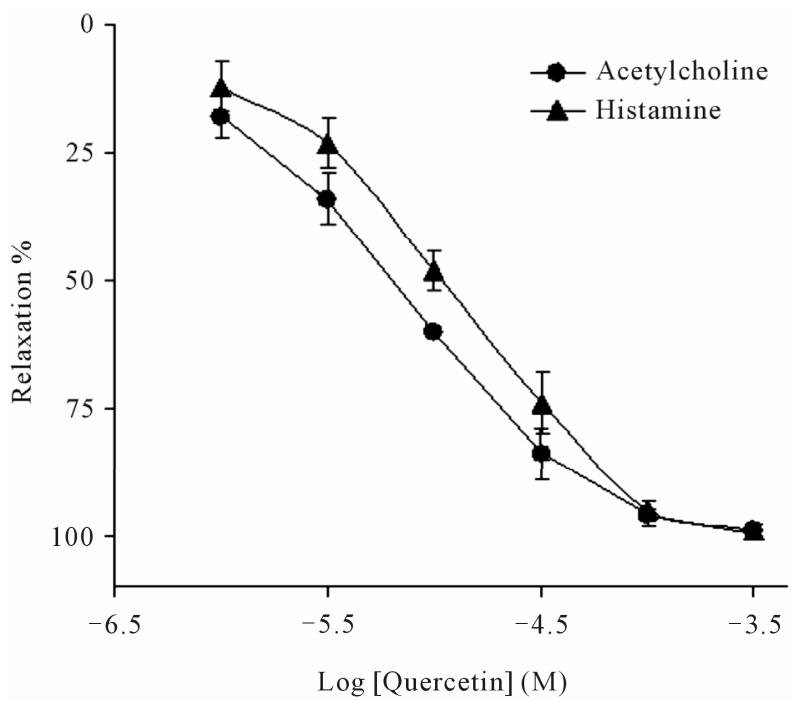

Figure 2. Concentration-effect curves of quercetin $\left(10^{-6}-3 \times\right.$ $\left.10^{-4} \mathrm{M}\right)$ on human bronchi rings precontracted to $50 \%$ $60 \%$ of maximal contraction with acetylcholine $\left(10^{-6} \mathrm{M}\right)$ or histamine $\left(10^{-5} \mathrm{M}\right)$. Results are expressed as percentages of the relaxation induced by aminophylline $3 \mathrm{mM}$. Each point represents the mean value \pm standard error of means (s.e.m.) from five experiments.

was performed on human bronchial rings precontracted with acetylcholine and histamine. These spasmogens were chosen because they are classically used not only in pulmonary pharmacology but are also two broncho-constricting agents involved in the contraction in human bronchial. The relaxant effect elicited by quercetin in human isolated bronchus, against the contractions induced by acetylcholine and histamine, was almost identical, with $\mathrm{pD}_{2}$ value of $5.2 \pm 0.1$ and $5.0 \pm 0.1$, respectively. Our results apparently agree with those reported in rat aorta $[11,16]$ and guinea-pig tracheal [21].

In addition, a concentration-dependent relaxation is observed with increasing cumulative concentrations of rutin, the quercetin-3-O-rutinoside, in human bronchial preparations precontracted with histamine and acetylcholine (Figures 3(a) and (b)). Compared with quercetin, the relaxation effect of rutin is weakly potentiated, with a maximum relaxation $\left(\mathrm{E}_{\max }\right)$ of $58 \% \pm 9 \%$ and $64 \% \pm 3 \%$ respectively on acetylcholine- and histamine-con- tracted human airways. On acetylcholine- and histamine- contracted human airways respectively, quercetin was more potent than rutin with an $\mathrm{EC}_{50}$ value of $6 \mu \mathrm{M}$ and $8 \mu \mathrm{M}$, in comparison with $\mathrm{EC}_{50}$ of rutin $10 \mu \mathrm{M}$ and $27 \mu \mathrm{M}$. The hydrophilicity or the presence of bulky oligosaccharide rutinose makes rutin unable to penetrate the cell membrane and might account for its ineffectiveness, as suggested by others works $[14,15]$.

At relatively high concentrations $>3 \times 10^{-5} \mathrm{M}$ of quercetin, the contractions induced by both contractile agonists were completely abolished (Figure 2). Hence, the 


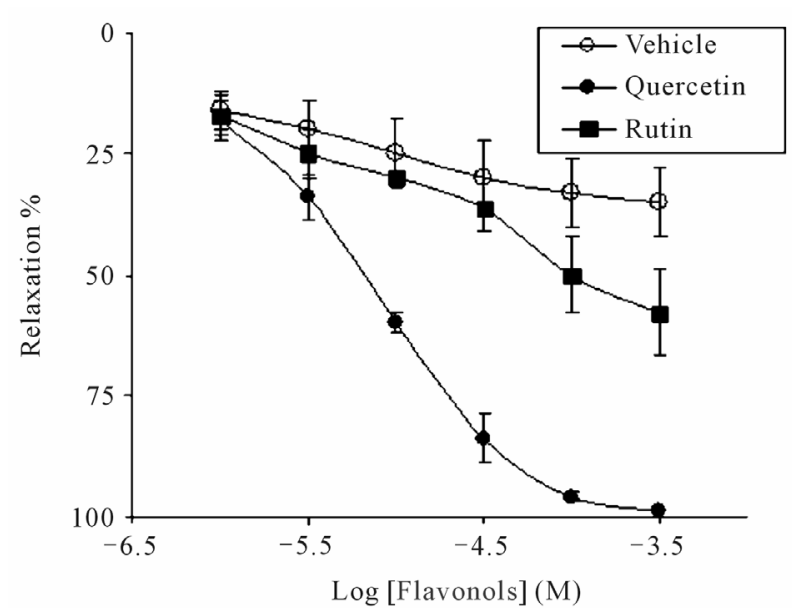

(a)

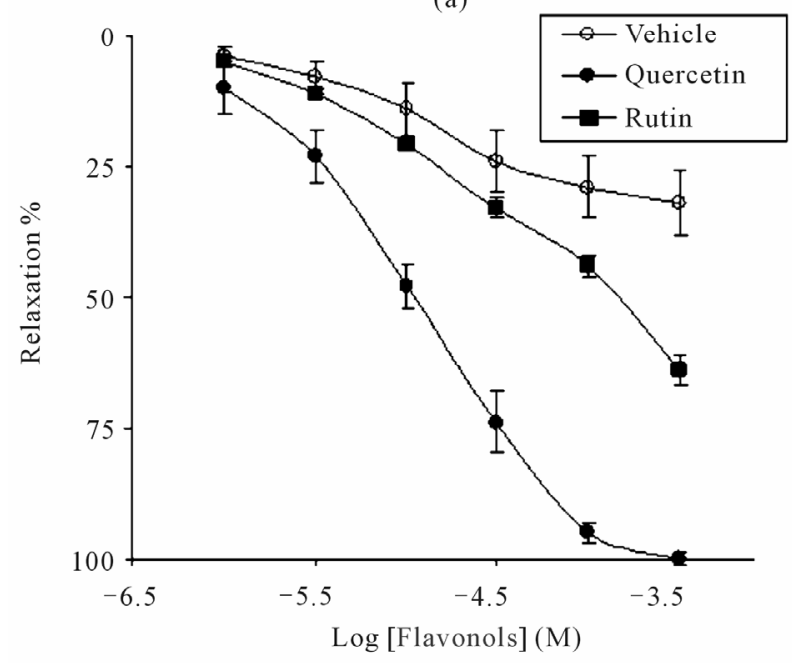

(b)

Figure 3. Cumulative concentration-relaxation curves for quercetin and rutin $\left(10^{-6}-3 \times 10^{-4} \mathrm{M}\right)$ in human bronchial rings precontracted to $50 \%-60 \%$ of maximal contraction with acetylcholine $\left(10^{-6} \mathrm{M}\right.$, panel a) or histamine $\left(10^{-5} \mathrm{M}\right.$, panel b). Results are expressed as percentages of the relaxation induced by aminophylline $3 \mathrm{mM}$. Each point represents the mean value \pm standard error of means (s.e.m.) of five to seven experiments.

lower concentrations $\leq 3 \times 10^{-5} \mathrm{M}$ were selected for study the mechanisms of bronchorelaxation action of this quercetin on human isolated bronchus.

In a series of experiments, the human bronchial rings were incubated with increasing $\mathrm{KCl}$ and calcium concentration in the absence and presence of different concentrations of quercetin or rutin. In control conditions, cumulative addition of $\mathrm{KCl}(3.75$ to $75 \mathrm{mM})$ or calcium $(0.01$ to $3 \mathrm{mM})$ produced contractile response of the human bronchial rings in a concentration-dependant manner (Figures 4(a) and (b)). Quercetin inhibited effectively and concentration-dependently these two ways of contraction in human airways preparations (Figures 4(a) and (b)). Quercetin, 3 and $10 \mu \mathrm{M}$, displaced and significantly

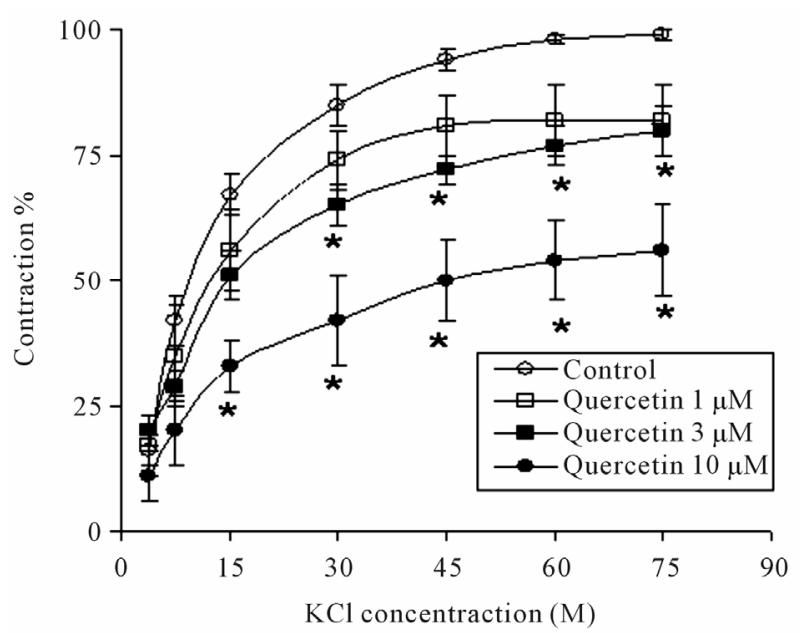

(a)

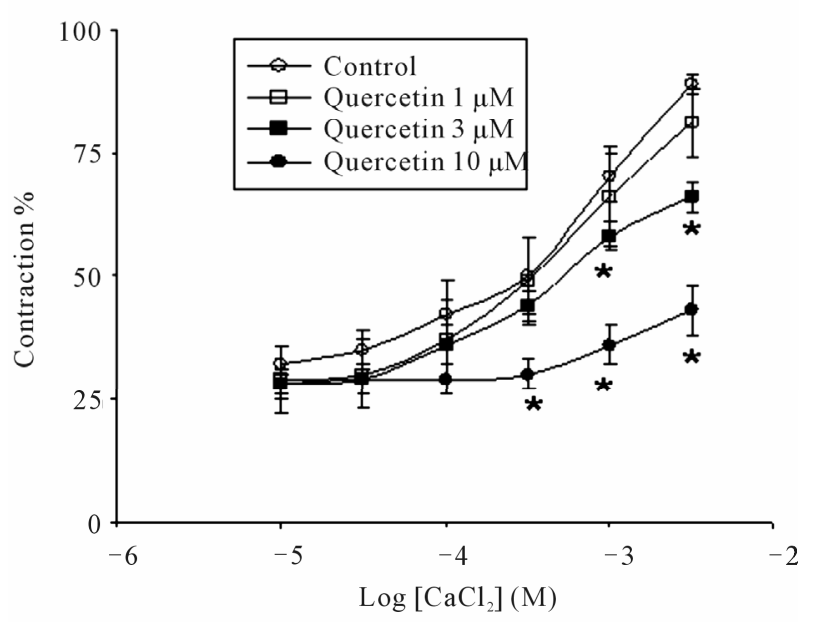

(b)

Figure 4. Concentration-response curves to $\mathrm{KCl}$ (a) and to $\mathrm{CaCl}_{2}$ (b) in human isolated bronchus incubated with increasing concentrations of quercetin. Each point represents the mean value \pm standard error of means (s.e.m.) of six experiments. *p $<0.05$.

$(\mathrm{p}<0.05)$ concentration-response curves to the right with depression of the maximal responses (Figures 4(a) and (b)). The $-\operatorname{logIC} \mathrm{C}_{50}$ values of quercetin against $\mathrm{KCl}(3 \times$ $\left.10^{-2} \mathrm{M}\right)$ and $\mathrm{CaCl}_{2}\left(10^{-3} \mathrm{M}\right)$-induced contractions were 7 $\mu \mathrm{M}$ and $4 \mu \mathrm{M}$, respectively. $\mathrm{K}^{+}$-induced contraction is result of an increase $\mathrm{Ca}^{2+}$ influx through L-type voltagedependent calcium channels (VDCC). They have reported that constriction of human bronchial muscle by acetylcholine, histamine, and pollen antigen challenge, was significantly reduced by nifedipine, a selective VDCC blocker [22]. Therefore, the inhibition of $\mathrm{K}^{+}$-induced contraction by quercetin might be interpreted as a consequence of blockade of VDCC. In fact, quercetin and related compounds, 3-O-methylquercetin and apigenin, are shown to be the potent inhibitors of $\mathrm{Ca}^{2+}$-up-take in vascular smooth muscle. In contrast, Duarte, et al. [23] 
found that, in rat aorta, the vasodilator effect of quercetin is unrelated to changes in cytosolic $\mathrm{Ca}^{2+}$. This latter observation suggests that the anti-spasmolytic effect of quercetin may be explained by its action with a second target beyond the $\mathrm{Ca}^{2+}$ channels. In fact, quercetin has been reported to inhibit $\mathrm{Ca}^{2+}$-sensitising mechanism in contractile proteins $[10,16,17,24]$. In contrast, rutin was devoid of inhibitory effect on the $\mathrm{K}^{+}$-induced contraction in human bronchial rings (data not shown).

The possible involvement of cAMP and cGMP-dependent protein kinases on the relaxant effect of quercetin was examined in the presence of isoprenaline, $\beta$-adrenoceptor agonist, and sodium nitroprusside (SNP), an activator of guanylate cyclase. On acetylcholine-contracted human bronchi, quercetin $\left(3 \times 10^{-5} \mathrm{M}\right)$ shifted the concentration-relaxation curves of isoprenaline to the left and significantly increased the potency $\left(\mathrm{pD}_{2}\right)$, as well as the efficacy $\left(E_{\max }\right)$ of isoprenaline (Table 1).

Furthermore, the relaxation elicited by sodium nitroprusside on acetylcholine-contracted human bronchial was significantly potentiated by quercetin $10^{-5} \mathrm{M}$ in terms of potency and efficacy (Table 1). This potentiating effect of quercetin on isoprenaline-elicited relaxation might be mediated via inhibition of cAMP-phosphodiesterase (PDE). Inhibition of cAMP-phosphodiesterase has been involved in the relaxing effect of quercetin on vascular and intestinal smooth muscle $[25,26]$. In rat aorta high concentrations of quercetin increased cyclic AMP levels [16]. Indeed, the 3-O-methylquercetine, a metabolite of quercetin, potentiates the relaxing effect of forskolin and SNP on the trachea of guinea pig and significantly inhibits the activity of cAMP- and cGMP-phosphodiesterase [21]. The potentiating effect of quercetin on SNP-evoked relaxation might not be due to its inhibitory effect on PDE-V activity, since they have been reported that quercetin has only low potency of PDE-V inhibition with $\mathrm{IC}_{50}>100 \mu \mathrm{M}$ [27]. However, quercetin is potent inhibitor of PDE III and IV, showing $\mathrm{IC}_{50}$ values of $5.6 \mu \mathrm{M}$ and $9.9 \mu \mathrm{M}$, respectively [27], which corresponded to the $\mathrm{EC}_{50}$ values producing its bronchodilator effect in the present study. Thus, our data suggested that the potentiated effect of relaxant activity of SNP by quercetin may be interpreted by increased the rate of cAMP. This subsequently activates the cAMP- dependent protein kinase and inhibits the myosin light chain kinase by phosphorylation and reducing the contraction [28]. The mechanism by which relaxation is produced by the cAMP pathway is not yet clear, but may result from the decrease in intracellular $\mathrm{Ca}^{2+}$. This decrease may be due to the reduction of the influx of $\mathrm{Ca}^{2+}$ by increasing its accumulation in the sarcoplasmsic reticulum, or extrusion through the plasma membrane [28]. However, the concentration-response curves to isoprenaline and to SNP were unaffected by rutin $10^{-4} \mathrm{M}$ (data not shown).
Table 1. Potentiating effect of quercetin on both isoprenaline- and sodium nitroprusside-induced relaxation of precontracted bronchus to $50 \%$ - $60 \%$ of maximal contraction with acetylcholine $\left(10^{-6} \mathrm{M}\right)$.

\begin{tabular}{lccc}
\hline & $\mathrm{n}$ & $\mathrm{pD}_{2}$ & $\mathrm{E}_{\max } \%$ \\
\hline Isoprenaline & 7 & $8.1 \pm 0.2$ & $93 \pm 4$ \\
Control & 5 & $8.5 \pm 0.1$ & $92 \pm 4$ \\
Quercetin $\left(10^{-5} \mathrm{M}\right)$ & 7 & $8.7 \pm 0.1^{*}$ & $97 \pm 2$ \\
Quercetin $\left(3 \times 10^{-5}\right)$ & & & \\
SNP & 7 & $6.1 \pm 0.2$ & $62 \pm 5$ \\
Control & 7 & $6.6 \pm 0.1^{*}$ & $77 \pm 6$ \\
Quercetin $\left(10^{-5} \mathrm{M}\right)$ &
\end{tabular}

Values are expressed as mean value \pm standard error of means (S.E.M.). $\mathrm{E}_{\max }$ are expressed as percentages of the relaxation induced by aminophylline $3 \mathrm{mM}$. The control preparations were treated with vehicle (DMSO) only. *Indicates significant differences between control and pretreated rings $(\mathrm{p}<$ $0.05)$.

Potential health effects of bioactive compounds depend on their bioavailability following oral administration. Although, the concentrations of quercetin reported effective in our study are higher from those observed in human plasma under various nutritional conditions [2932], those concentrations may be achieved in the body with diet containing high flavonols dietary supplements [33]. Furthermore, the half-life of quercetin is on the order of $10-30 \mathrm{~h}[32,34]$, thus repeated consumption of foods rich in quercetin (such as onions or apples) might cause its accumulation in blood at levels similar to those found effective in the present study.

In conclusion, the data presented in this study indicate that quercetin, the most abundantly consumed bioflavonoid, is able to evoke airway smooth muscle relaxation. Although the mode of action remains to be clarified, our findings support the view that mechanisms of relaxant effects were mediated by an increase in cytosolic nucleotide cyclic levels possibly via nonselective inhibition of phosphodiesterases as well as an alteration in availability of $\mathrm{Ca}^{2+}$ to the contractile machinery. Like many biochemical effects have been attributed to quercetin, we can not rule out its ability to interfere with crucial enzyme systems involved in airways contraction. Moreover, the bronchorelaxing properties of quercetin observed in this study support the epidemiological data, which postulate an inverse relationship between consumption of dietary flavonoids and the incidence of obstructive lung disease.

\section{Acknowledgements}

This work was supported by the Algerian Ministry of Higher Education and Scientific Research (MESRS) and 
by the Algerian Agency for the Development of Research in Health (ANDRS).

\section{REFERENCES}

[1] I. C. Arts and P. C. Hollman, "Polyphenols and Disease Risk in Epidemiologic Studies," The American Journal of Clinical Nutrition, Vol. 81, No. 1, 2005, pp. 317S-325S.

[2] M. G. L. Hertog, E. J. M. Feskens, P. C. H. Hollman, M. B. Katan and D. Kromhout, "Dietary Antioxidant Flavonoids and Risk of Coronary Heart Disease: The Zutphen Elderly Study," Lancet, Vol. 342, 1993, pp. 1007-1011. doi:10.1016/0140-6736(93)92876-U

[3] P. C. H. Hollman and I. C. W. Arts, "Flavonols, Flavones and Flavanols: Nature, Occurrence and Dietary Burden," Journal of the Science of Food and Agriculture, Vol. 80, No. 7, 2000, pp. 1081-1093. doi:10.1002/(SICI)1097-0010(20000515)80:7<1081::AID -JSFA566>3.0.CO;2-G

[4] Y. J. Yang, Z. L. Yang, D. C. Wang, X. C. Xiao and P. Li, "Comparative Study on Effects of Rutin and Quercetin on Metabolism in Osteoblast Cells," Zhong Yao Cai, Vol. 29, No. 5, 2006, pp. 467-470.

[5] J. Terao and M. K. Piskula, "Flavonoids as Inhibitors of Lipid Peroxidation in Membranes," In: C. A. Rice-Evans, L. Packer, Eds., Flavonoids in Health and Disease, Marcel Dekker, New York, Basel, 1998, 277-293.

[6] A. Scalbert, I. T. Johnson and M. Saltmarsh, "Polyphenols: Antioxidants and Beyond," The American Journal of Clinical Nutrition, Vol. 81, No. 1, 2005, pp. 215S-217S.

[7] C. Tabak, I. C. Arts, H. A. Smit, D. Heederik and D. Kromhout, "Chronic Obstructive Pulmonary Disease and Intake of Catechins, Flavonols, and Flavones: The MORGEN Study," American Journal of Respiratiory and Criticle Care Medicine, Vol. 164, No. 1, 2001, pp. 61-64.

[8] P. Knekt, J. Kumpulainen, R. Järvinen, H. Rissanen, M. Heliövaara, A. Reunanen, T. Hakulinen and A. Aroma, "Flavonoid Intake and Risk of Chronic Diseases," The American Journal of Clinical Nutrition, Vol. 76, No. 3, 2002, pp. 560-568.

[9] C. Walda, C. Tabak, H. A. Smit, L. Räsänen, F. Fidanza, A. Menotti, A. Nissinen, E. J. M. Feskens and D. Kromhout, "Diet and 20-Year Chronic Obstructive Pulmonary Disease Mortality in Middle-Aged Men from Three European Countries," European Journal of Clinical Nutrition, Vol. 56, No. 7, 2002, pp. 638-643. doi:10.1038/sj.ejen. 1601370

[10] F. Pérez-Vizcaino, M. Ibarra, A. L. Cogolludo, J. Duarte, F. Zaragoza-Arnaez, L. Moreno, G. Lopez-Lopez and J. Tamargo, "Endothelium-Independent Vasodilator Effects of the Flavonoid Quercetin and Its Methylated Metabolites in Rat Conductance and Resistance Arteries," Journal of Pharmacology and Experimental, Vol. 302, No. 1, 2002, pp. 66-72. doi:10.1124/jpet.302.1.66

[11] F. Fusi, S. Saponara, F. Pessina, B. Gorelli and G. Sgaragli, "Effects of Quercetin and Rutin on Vascular Preparations: A Comparison between Mechanical and Electrophysiological Phenomena," European Journal of Nutri- tion, Vol. 42, No. 1, 2003, pp. 10-17. doi:10.1007/s00394-003-0395-5

[12] W. D. H. Chiwororo and J. O. A. Ojewole, "Dual Effects of Quercetin on Rat Isolated Portal Vein Smooth Muscle Contractility," Cardiovascular Journal of Africa, Vol. 21, No. 3, 2010, pp. 132-136.

[13] P. J. Macander, "Flavonoids Affect Acetylcholine, Prostaglandin E2 and Antigen-Mediated Smooth Muscle Contraction," Progress in Clinical and Biological Research, Vol. 213, 1986, pp. 489-492.

[14] W.-C. Ko, P.-Y. Liu, J.-L. Chen, I.-J. Leu and C.-M. Shih, "Relaxant Effects of Flavonoids in Isolated Guinea Pig Trachea and Their Structure-Activity Relationships," Planta Medica, Vol. 69, No. 12, 2003, pp. 1086-1090. doi:10.1055/s-2003-45187

[15] Y. C. Xu, S. W. S. Leung, D. K. Y. Yeung, L. H. Hu, G. H. Chen, C. M. Che and R. Y. K. Man, "Structure Activity Relationships of Flavonoids for Vascular Relaxation in Porcine Coronary Artery," Phytochemistry, 2007, Vol. 68, No. 8, pp. 1179-1188. doi:10.1016/j.phytochem.2007.02.013

[16] J. Duarte, F. Perez-Vizcaino, A. Zarzuelo, J. Jiménez and J. Tamargo, "Vasodilator Effects of Quercetin in Isolated Rat Vascular Smooth Muscle," European Journal Pharmacology, Vol. 239, No. 1-3, 1993, pp. 1-7. doi:10.1016/0014-2999(93)90968-N

[17] E. J. Middleton, C. Kandaswami and T. C. Theoharides, "The Effects of Plant Flavonoids on Mammalian Cells: Implications for Inflammation, Heart Disease, and Cancer," Pharmacological Reviews, Vol. 52, No. 4, 2000, pp. 673-751.

[18] V. Calderone, S. Chericoni, C. Martinelli, L. Testai, A. Nardi, I. Morelli, M. C. Breschi and E. Martinotti, "Vasorelaxing Effects of Flavonoids: Investigation on the Possible Involvement of Potassium Channels," NaunynSchmiedeberg's Archives of Pharmacology, Vol. 370, No. 4, 2004, pp. 290-298. doi:10.1007/s00210-004-0964-Z

[19] R. W. Foster, R. C. Small, A. H. Weston, "Evidence That the Spasmogenic Action of Tetraethylammonium in Guinea-Pig Trachealis is Both Direct and Dependent on the Cellular Influx of Calcium Ion," British Journal Pharmacology, Vol. 79, No. 1, 1983, pp. 255-263.

[20] C. Advenier, J. Cerrina, P. Duroux, A. Floch and A. Renier, "Effects of Five Different Organic Calcium Antagonists on Guinea-Pig Isolated Trachea," British Journal Pharmacology, Vol. 82, No. 3, 1984, pp. 727-733.

[21] W.-C. Ko, H.-L. Wang, C.-B. Lei, C.-H. Shih, M.-I. Chung and C.-N. Lin, "Mechanisms of Relaxant Action of 3-O-Methylquercetin in Isolated Guinea Pig Trachea," Planta Medica, Vol. 68, No. 1, 2002, pp. 30-35. doi:10.1055/s-2002-20059

[22] T. Ahmed and W. M. Abraham, "Role of Calcium-Channel Blockers in Obstructive Airway Disease," Chest, Vol. 88, No. 2, 1985, pp. 142S-151S.

[23] J. Duarte, F. Perez-Vizcaino, A. Zarzuelo, J. Jimenez and J. Tamargo, "Inhibitory Effects of Quercetin and Staurosporine on Phasic Contractions in Rat Vascular Smooth Muscle," European Journal of Pharmacology, Vol. 262, 
No. 1-2, 1994, pp. 149-156. doi:10.1016/0014-2999(94)90038-8

[24] H. Masatoshi, I. Shigeo, T. Toshio, N, Kazuo, I. Masaaki and H. Hiroyoshi, "Differential Effects of Flavonoids as Inhibitors of Tyrosine Protein Kinases and Seine/Threonine Protein Kinases," Biochemical Pharmcology, Vol. 37, No. 15, 1988, pp. 2987-2992. doi:10.1016/0006-2952(88)90286-9

[25] A. Beretz, J. Stoclet and R. Anton, "Inhibition of Isolated Rat Aorta Contraction by Flavonoids: Possible Correlation with Cyclic AMP-Phosphodiesterase Inhibition," Planta Medica, Vol. 39, 1980, pp. 236-242.

[26] T. Nikaido, T. Ohmoto, U. Sankawa, T. Hamanaka and K. Totsuka, "Inhibition of Cyclic AMP Phosphodiesterase by Flavonoids," Planta Medica, Vol. 46, No. 11, 1982, pp. 162-166. doi:10.1055/s-2007-970043

[27] W.-C. Ko, C.-M. Shih, Y.-H. Lai, J.-H. Chen and H.-L. Huang, "Inhibitory Effects of Flavonoids on Phosphodiesterase Isozymes from Guinea Pig and Their StructureActivity Relationships," Biochemical Pharmacology, Vol. 68, No. 10, 2004, pp. 2087-2094. doi:10.1016/j.bcp.2004.06.030

[28] D. P. Westfall, W. T. Gerthoffer and R. C. Webb, "Vasodilators and Nitric Oxide Synthase," In: T. M. Brody, J. Larner and K. P. Minnerman, Eds., Human Pharmacology Molecular to Clinical, Mosby, Saint Louis, 1998, pp 239-247.

[29] C. Manach, C. Morand, V. Crespy, C. Demigné, O. Texier, F. Régérat and C. Rémésy, "Quercetin is Recovered in Human Plasma as Conjugated Derivatives Which Re- tain Antioxidant Properties," FEBS Letters, Vol. 426, No. 3, 1998, pp. 331-336. doi:10.1016/S0014-5793(98)00367-6

[30] J. Lee, Z. Y. Wang, H. Li, L. Chen, Y. Sun, S. Gobbo, D. A. Balentine and C. S. Yang, "Analysis of Plasma and Urinary Tea Polyphenols in Human Subjects," Cancer Epidemiol, Biomarkers \& Prevention, Vol. 4, No. 4, 1995, pp. 393-399.

[31] D. Rein, S. Lotito, R. R. Holt, C. L. Keen, H. H. Schmitz and C. G. Fraga, "Epicatechin in Human Plasma: In Vivo Determination and Effect of Chocolate Consumption on Plasma Oxidation Status," Journal of Nutrition, Vol. 130, No. 8, 2000, pp. 2109S-2114S.

[32] E. U. Graefe, J. Wittiig, S. Mueller, A. K. Riethling, B Uehleke, B. Drewelow, H. Pforte, G. Jacobash, H. Derendorf and M. Veit, "Pharmacokinetics and Bioavailability of Quercetin Glycosides in Humans," Journal of Clinical Pharmacology, Vol. 41, No. 5, 2001, pp. 492- 499. doi:10.1177/00912700122010366

[33] W. Waïtjen, G. Michels, B. Steffan, P. Niering, Y. Chovolou, A. Kampkötter, Q.-H. Tran-Thi, P. Proksch and R. Kahl, "Low Concentrations of Flavonoids are Protective in Rat H4IIE Cells Whereas High Concentrations Cause DNA Damage and Apoptosis," Journal of Nutrition, Vol 135, No. 3, 2005, pp. 525-531.

[34] P. C. Hollman, J. H. de Vries, S. D. van Leeuwen, M. J. Mengelers and M. B. Katan, "Absorption of Dietary Quercetin Glycosides and Quercetin in Healthy Ileostomy Volunteers," The American Journal of Clinical Nutrition, Vol. 62, No. 6, 1995, pp. 1276-1282. 